\title{
O CONFLITO SOCIAL E POLÍTICO NAS HIDRELÉTRICAS DA BACIA DO URUGUAI
}

\section{Humberto José da Rocha}

Universidade Federal da Fronteira Sul (UFFS), Chapecó - SC, Brasil. E-mail: humbertojosedarocha@yahoo.com.br

\section{Hemerson Luiz Pase}

Universidade Federal de Pelotas (UFPel), Pelotas - RS, Brasil. E-mail: hemerson.pase@gmail.com

DOI: http//dx.doi.org/10.17666/308899-113/2015

\section{Introdução}

A hidreletricidade corresponde a aproximadamente $85 \%$ da energia elétrica consumida no Brasil atualmente. As usinas hidrelétricas de energia (UHEs) em operação no país somam 196 empreendimentos, ${ }^{1}$ em um quadro de expansão do setor para os próximos anos, tendo em vista os projetos em estudo e instalação (Aneel/BIG, 2014). Essas obras implicam em grandes áreas atingidas pela formação dos reservatórios, instalação dos canteiros de obras, estradas para circulação de pessoal, material e linhas de transmissão de energia que, entre as externalidades, têm no "deslocamento compulsório" ${ }^{2}$ um ponto nevrálgico da discussão no sentido socioambiental.

Mesmo em análise específica sobre determinada hidrelétrica, é fundamental a consciência de que esta se encontra no interior de um processo social que "re-

Aprovado em 06/03/2015 fere-se às transformações amplas, contínuas, de longa duração, ou seja, em geral não aquém de três geraçôes" (Elias, 2006 p. 27), no qual o caso estudado é condicionante e condicionado respectivamente. Além disso, é adequado interpretar empreendimentos dessa natureza como integrantes de uma política pública de infraestrutura que é produzida a partir de uma intensa correlação de poder, não raras vezes contraditória e que, quando em instalação, impulsiona também o debate e, muitas vezes, a conflagração política.

$\mathrm{Na}$ bacia do rio Uruguai, pode-se perceber reflexos do processo de instalação das UHE Itaipu (Brasil/ Paraguai) e Passo Real (rio Jacuí), que, apesar de localizadas em outras bacias hidrográficas, influenciaram significativamente o processo de instalação e mobilização social na UHE Itá (RS/SC), referência na bacia hidrográfica. Da mesma forma, mas tomando apenas a própria bacia, podemos notar reflexos da UHE Itá sobre as subsequentes, como as UHE Machadinho (RS/ SC), Barra Grande (RS/SC), Campos Novos (SC), até 
chegar ao caso da UHE Foz do Chapecó, mais recente, onde podemos perceber mudanças na estratégia tanto daqueles que defendem a obra quanto daqueles contrários a ela, ambos em decorrência de experiências no mencionado processo social (Rocha, 2013).

Considerando cada nova hidrelétrica ao longo do processo social, podemos perceber reconfiguraçôes sociais que seguem tendências mínimas no sentido da disposição das alianças e rivalidades entre os agentes sociais. Diante da complexidade da sociedade atual, sobretudo em relação ao tema estudado, observamos essas tendências segundo a ideia de "projetos políticos" que, com inspiração gramsciniana, Dagnino, Olvera e Panfichi (2006, p. 199) apresentam "para designar os conjuntos de crenças, interesses, concepções de mundo, representações do que deve ser a vida em sociedade, que orientam a ação política dos diferentes sujeitos". Transportando essa ideia para a questão hidrelétrica, podemos identificar dois projetos distintos, o neoliberal e o democrático-participativo, os quais não serão tomados como grupos fechados, mas ajudam a orientar a análise de forma a distinguir a natureza das ações dos agentes envolvidos. Dessa forma, mesmo que destinemos seçōes específicas no decorre deste trabalho, convém uma breve caracterização desses projetos e seus respectivos signatários.

$\mathrm{Na}$ perspectiva do projeto neoliberal, "o primado do mercado, enquanto eixo reorganizador da economia é visto como devendo se estender ao conjunto da sociedade", que a partir de preceitos mercadológicos orientaria sua vida nos diferentes campos (Idem, p. 55). No tocante às hidrelétricas, este é representado principalmente por consórcios formados pelo Estado e por empresas de capital privado, alianças que têm se consolidado através das Sociedades de Propósito Específico (SPEs). ${ }^{3}$

$\mathrm{Na}$ ótica do projeto democrático-participativo, "a participação da sociedade nos processos de decisão assume um papel central", sendo vista como "instrumento da construção de uma maior igualdade" e "cidadania”, onde se articulariam demandas específicas de cada grupo social e da sociedade em seu conjunto (Idem, pp. 48-52). Na questão das hidrelétricas, este projeto é representado principalmente pelo Movimento dos Atingidos por Barragens (MAB), no sentido de contestação ao projeto barrageiro.
Com base nesse panorama geral, abordamos a questão hidrelétrica, especialmente o remanejamento populacional, sob a luz do conflito entre os consórcios e o MAB, levando em conta as modalidades de remanejamento populacional previstas nas principais hidrelétricas da bacia hidrográfica, a saber, "indenização em dinheiro", "carta de crédito", "reassentamento em áreas remanescentes", "pequenos reassentamentos" e "reassentamento rural coletivo". 4

Tendo em vista a processualidade e a natureza conflitiva da questão hidrelétrica, nosso objetivo é compreender em que medida essas modalidades de remanejamento populacional refletem na sequência do processo social da hidreletricidade na bacia do Uruguai. Como objetivo específico, pretendemos verificar em que medida a população atingida, segundo as modalidades em que foram remanejados, participa de mobilizações posteriores ao seu remanejamento, procurando assinalar os argumentos para tais iniciativas.

Além da revisão bibliográfica acerca do remanejamento populacional, nossa discussão fundamenta-se, sobretudo, em pesquisa de campo realizada no âmbito do P\&D 3936-003/2007 da Aneel, intitulado "Avaliação dos resultados e proposição de modelo de elaboração de programas de remanejamento da população atingida por empreendimentos hidrelétricos". Em julho de 2011, um grupo de cinco pesquisadores, entre os quais os autores deste trabalho, foi a campo para realizar entrevistas em profundidade e testar a viabilidade de um survey específico para o desenvolvimento do referido projeto. Os entrevistados foram selecionados a partir do conhecimento empírico de um dos pesquisadores que, desde 2007, desenvolvia um projeto de doutoramento sobre o tema na bacia do Uruguai.

Dos resultados qualitativos e com o aprimoramento do survey, retornamos para outra pesquisa de campo durante o mês de janeiro de 2012 sendo que contamos com a participação de mais dezessete alunos de graduação e pós-graduação das Universidades Federal de Pelotas e da Fronteira Sul. Desta vez, realizamos entrevistas quantitativas com 632 famílias remanejadas pelas hidrelétricas de Itá, Machadinho, Barra Grande, Campos Novos e Foz do Chapecó sendo que os dados foram trabalhados quantitativamente através do programa SPSS. ${ }^{5}$

Em vista dos objetivos do projeto de pesquisa, tomamos a precaução de entrevistar famílias remanejadas 
pelas diferentes modalidades disponíveis. Neste texto, analisamos mais detidamente a modalidade "reassentamento rural coletivo" (RRC), por entendermos que se trata da categoria defendida pelo MAB. Nesta esfera específica, o movimento social tem uma participação mais efetiva e o projeto democrático-participativo pode garantir a "multiterritorialização" da luta.

Estruturamos este trabalho de forma a apresentar um panorama geral da proposta segundo a realidade da questão hidrelétrica brasileira. Delineamos, a seguir, na bacia do Uruguai, nosso locus de pesquisa, os "pontos de poder" representados por agentes sociais identificados com projetos políticos distintos. Na sequência, identificamos respectivamente os principais representantes dos dois projetos políticos em questão: primeiro, as SPEs, seus agentes e ações, tendo as hidrelétricas como pontos de referência; segundo, o MAB, tendo os reassentamentos como principal referência. A coexistência dessas duas perspectivas nos permitiu analisar como se deu a "multiterritorialização" do conflito e, assim, compilamos os resultados da pesquisa discutidos nas consideraçôes finais.

\section{A bacia do Uruguai como uma "malha" para análise}

A Lei n. 9074, de 7 de julho de 1995, que "Estabelece normas para outorga e prorrogaçôes das concessōes e permissões de serviços públicos e dá outras providências", define no artigo $5^{\circ}, \$ 2^{\circ}$, que "nenhum aproveitamento hidrelétrico poderá ser licitado sem a definição do 'aproveitamento ótimo' pelo poder concedente". Este conceito de "aproveitamento ótimo" é definido no $\$ 3^{\circ}$ da mesma Lei como sendo "todo potencial definido em sua concepçáo global pelo melhor eixo do barramento, arranjo físico geral, níveis d'água operativos, reservatório e potência, integrante da alternativa escolhida para divisão de quedas de uma bacia hidrográfica" (Brasil, 1995). Em outras palavras, trata-se do melhor ponto de um rio para a exploração hidrelétrica do ponto de vista técnico.

Tal conceito relaciona-se com a ideia de Raffestin de que "o homem não se interessa pela matéria como massa inerte indiferenciada, mas na medida em que ela possui propriedades que correspondem a utilidades", neste caso, a geração de energia. Para além do aspecto técnico, preponderante neste conceito, Raffestin afirma que "a relação que faz surgir um recurso não é puramente instrumental, mas também política" (1993, p. 225). Com base nessa ideia, configuram-se possíveis palcos de conflito entre agentes sociais que podem ser identificados sob a luz dos dois projetos mencionados anteriormente.

Determinado o local de "aproveitamento ótimo", o setor elétrico busca acessar tal espaço privilegiado para a instalação da hidrelétrica. Nicolas (1996, p. 85) defende que "cada apropriação do espaço implica uma nova atribuição de coerência, de uma nova lógica que adquire conteúdo com um devir social específico, no qual se tecem o individual e o coletivo". Nesse sentido, a instalação de uma hidrelétrica significa a reconfiguração geográfica e social do local, onde coexistem duas lógicas distintas de apropriação. Uma é a dos atingidos que, como agricultores familiares, vivem sob um "modelo tecnológico sumamente simples, embora ao mesmo tempo complexo, já que não só não está submetido à busca de transformaçóes permanentes como se constitui na lenta evolução e, sobretudo, na adaptação do modelo tecnológico às condiçōes do espaço", sendo que sua manutenção é defendida pelo MAB. A outra lógica é condizente com as SPEs, baseada em uma "visão desenvolvimentista" sobre a qual "realiza-se um trabalho tecnológico não destinado a melhorar a permanência das formas espaço-temporais, mas orientada para acelerar a mudança e intensificar temporalmente a apropriação do espaço" (Idem, pp. 86-88).

O conflito entre essas duas lógicas de apropriação do espaço, condizentes com os dois projetos políticos distintos, coexistem - ou disputam - nesses locais de "aproveitamento ótimo". O estabelecimento de usinas, portanto, gera disputas específicas em cada local, mas que, no todo, acabam assumindo a "dimensão de uma malha", que "nunca é - ou quase nunca - aleatória, pois cristaliza todo um conjunto de fatores, dos quais uns são físicos, outros humanos: econômicos, políticos, sociais e culturais". É sob esta ótica relacional que entendemos cada hidrelétrica como um "local de poder" ou pontos em que "se definem melhor em termos relativos que em absolutos" (Raffestin, 1993, pp. 155-156).

Tendo em vista que a instalação de hidrelétricas compreende um processo social amplo, a "malha" daí resultante é composta não só por questōes 
identificadas em cada usina, mas também pelos "reassentamentos rurais coletivos". Como vimos, o deslocamento compulsório é inerente a essas obras de grande escala; isso significa que cada hidrelétrica ou reassentamento pode originar um novo "local de poder", uma vez que a população atingida muitas vezes se reagrupa em locais próximos a hidrelétricas futuras. Um caso exemplar refere-se aos re- manejados da UHE Itá, que foram reassentados no município de Campos Novos em Santa Catarina, onde já havia projeto para a instalação de outra usina, o que acabou se confirmando. $O$ processo social na bacia hidrográfica do rio Uruguai foi assim se configurando ao tecer a "malha" que reúne as hidrelétricas e os respectivos reassentamentos, como mostra a Figura 1.

Figura 1

Mapa da Bacia Hidrográfica do Rio Uruguai

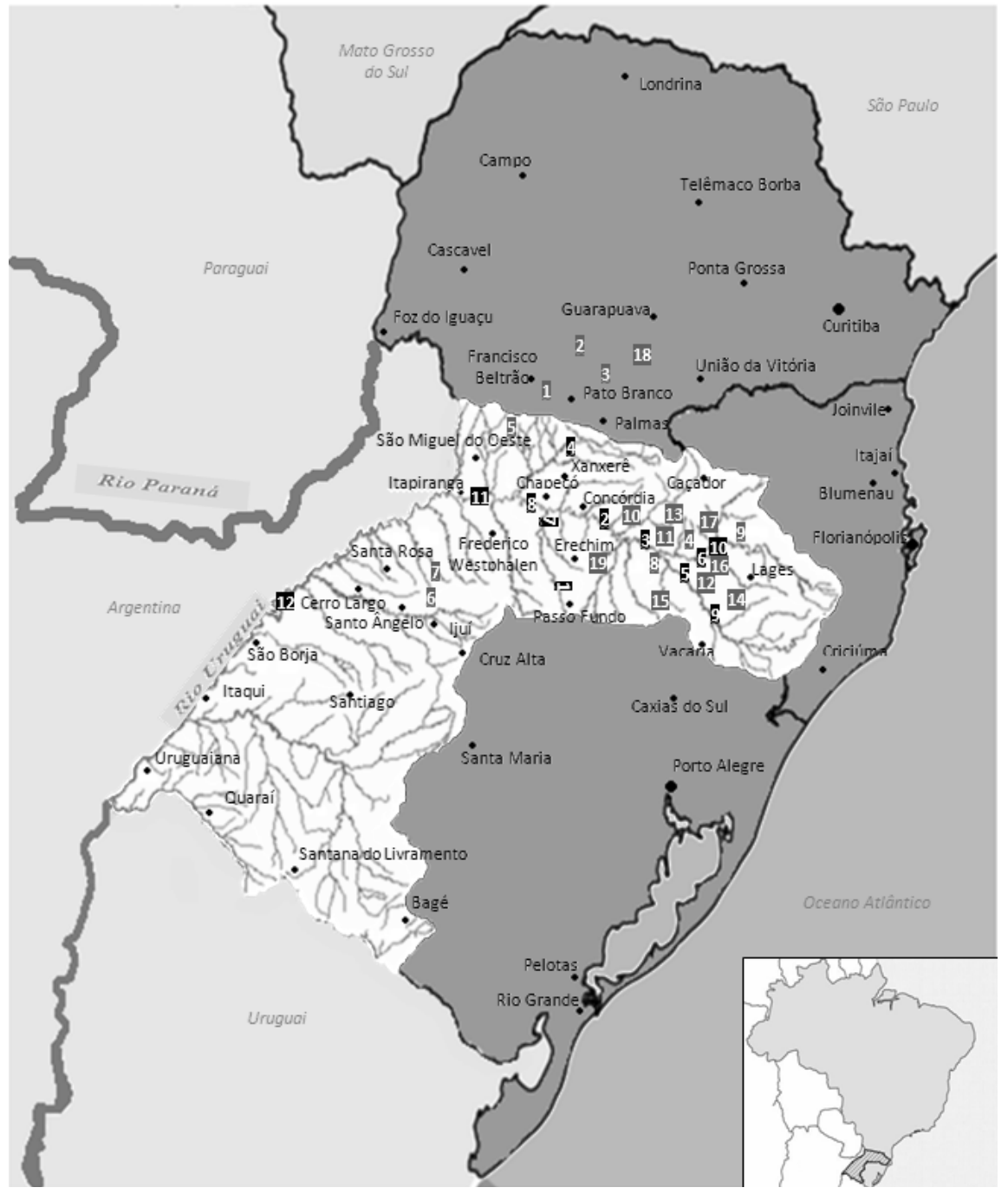

As principais hidrelétricas da bacia hidrográfica do rio Uruguai: 1 - UHE Passo Fundo; 2 - UHE Itá; 3 - UHE Machadinho; 4 - Quebra-Queixo; 5 - UHE Barra Grande; 6 - UHE Campos Novos; 7 - UHE Monjolinho; 8 - UHE Foz do Chapecó; 9 - UHE Pai Querê; 10 - Garibaldi; 11 - UHE Itapiranga; 12 - UHE Garabi.

Fonte: Elaborado pelos autores. 
Complementarmente, o Quadro 1 auxilia na compreensão do mapa apresentando a correspondência numérica dos pontos referentes aos reassentamentos e as hidrelétricas de que são oriundos, sua localização e população.

\section{Quadro 1}

\section{As UHEs e seus Respectivos Reassentamentos Rurais Coletivos (RRCs)}

\begin{tabular}{|c|c|c|c|}
\hline UHE (entrada em operação) & Município (n. mapa) & RRC & Famílias \\
\hline \multirow{8}{*}{$\begin{array}{l}\text { UHE Itá } \\
(2000)\end{array}$} & Marmeleiro-PR (1) & Marmeleiro & 32 \\
\hline & Mangueirinha-PR (18) & Mangueirinha/Itá & 82 \\
\hline & Chopinzinho-PR (2) & Chopinzinho & 74 \\
\hline & Honório Serpa-PR (3) & Honório Serpa & 38 \\
\hline & Campos Novos-SC (4) & Campos Novos/Itá & 28 \\
\hline & Campo Erê-SC (5) & Campo Erê & 50 \\
\hline & Catuípe-RS (6) & Catuípe & 74 \\
\hline & Chiapetta-RS (7) & Chiapeta & 66 \\
\hline Subtotal & 08 & 08 & 444 \\
\hline \multirow{10}{*}{$\begin{array}{l}\text { UHE Machadinho } \\
\text { (2001) }\end{array}$} & \multirow[t]{4}{*}{ Barracão-RS (8) } & Barracão I & 29 \\
\hline & & Barracão II & 20 \\
\hline & & Barracão III & 59 \\
\hline & & Barracão Belo/Betiollo & 5 \\
\hline & Curitibanos-SC (9) & Curitibanos & 33 \\
\hline & \multirow[t]{2}{*}{ Campos Novos-SC (4) } & Campos Novos/Machadinho & 29 \\
\hline & & Campos Novos/Menegatti & 13 \\
\hline & Capinzal-SC (10) & Capinzal & 10 \\
\hline & Erechim-RS (19) & Erechim & 8 \\
\hline & Zortéa-SC (11) & Zortéa & 7 \\
\hline Subtotal & 06 & 10 & 213 \\
\hline \multirow{7}{*}{$\begin{array}{l}\text { UHE Barra Grande } \\
(2005)\end{array}$} & Campo Belo do Sul-SC (12) & Barra do Imigrante & 37 \\
\hline & \multirow[t]{3}{*}{ Anita Garibaldi-SC (13) } & Anita Garibaldi & 15 \\
\hline & & Santa Catarina & 24 \\
\hline & & 15 de Fevereiro & 16 \\
\hline & Capão Alto-SC (14) & Capão Alto & 33 \\
\hline & \multirow[t]{2}{*}{ Esmeralda-RS (15) } & Esmeralda I & 35 \\
\hline & & Esmeralda II & 31 \\
\hline Subtotal & 04 & $\mathbf{0 7}$ & 191 \\
\hline \multirow{3}{*}{ UHE Campos Novos (2006) } & \multirow[t]{2}{*}{ Celso Ramos-SC (16) } & MAB & 59 \\
\hline & & Enercan & 22 \\
\hline & Cerro Negro (17) & Enercan & 18 \\
\hline Subtotal & 02 & 03 & 99 \\
\hline UHE Foz do Chapecó (2010) & Mangueirinha-PR (18) & Mangueirinha/FzCh & 44 \\
\hline Total & 19 & 29 & 991 \\
\hline
\end{tabular}

Fonte: Elaborado pelos autores com base em pesquisa de campo 
Cada "local de poder" da malha que compõe a bacia do rio Uruguai pode ser identificado por uma hidrelétrica ou um reassentamento. As UHEs representam a cristalização da lógica desenvolvimentista ancorada em um projeto neoliberal que reúne empresas públicas e privadas de diferentes partes do mundo, atuantes no espaço de implementação das usinas por intermédio das SPEs. Os "reassentamentos rurais coletivos", em contrapartida, apoiados nas ações do $\mathrm{MAB}$, representam a concretização do projeto político democrático-participativo.

A seguir, analisaremos mais detidamente cada um dos agentes envolvidos no processo de instalação de uma hidrelétrica a partir de suas ações e identificação com os projetos políticos mencionados.

\section{As hidrelétricas como "pontos de poder"}

As hidrelétricas são "oportunidades únicas para se promover, num contexto regulamentado, a articulação do capital internacional e nacional sob a supervisão de diferentes Estados nacionais e de organizações supranacionais", sendo que o "consórcio é a entidade social, econômica e política concreta que opera esta articulação" (Ribeiro, 1991, p. 102). Daí a vinculação já mencionada com um projeto político neoliberal. Mas isso não significa o engessamento dessas estruturas. Ao contrário, o que se assiste é a capacidade de "desterritorialização" inerente a essas "estruturas de poder econômico, político, social e cultural internacionais, mundiais ou globais descentradas". Elas se fazem "presentes em muitos lugares, nações, continentes, parecendo flutuar por sobre Estados e fronteiras, moedas e línguas, grupos e classes, movimentos sociais e partidos políticos" (Ianni, 1997, pp. 93-94).

No caso da América Latina, especialmente em relação ao Brasil, as "estratégias de desenvolvimento" promovidas pelo fórum de Integração da Infraestrutura Regional Sul-americana (IIRSA) e pelo Programa de Aceleração do Crescimento (PAC) - visam fomentar projetos de grande escala que têm na energia um de seus pontos fundamentais, concretizando a chamada desterritorialização do poder (Verdum, 2007). O fórum de integração da América do Sul foi firmado em setembro de 2000 em Brasília, reu- nindo doze países sul-americanos com o intuito de definir "uma estratégia de trabalho conjunto visando à integração das infraestruturas nacionais" (Idem, pp. 17-18). Além dos Estados, Ricardo Verdum (2007, p. 22) destaca instituições financeiras como o Banco Mundial (Bird), o Banco Nacional de Desenvolvimento Econômico e Social (BNDES) e empresas de grande porte, entre as quais General Eletric, América Latina Logística, Vale do Rio Doce, Odebrecht, Petrobras, Andrade Gutiérrez e Queiroz Galvão, algumas envolvidas diretamente em hidrelétricas na bacia do rio Uruguai. Nesse contexto, o Brasil lançou em janeiro de 2007 o PAC, que tem como objetivo a aceleração da economia e a modernização tecnológica, aumentando a competitividade do Brasil e promovendo sua integração interna e com outros países (Idem, p. 28). Constata-se, assim, que projetos de grande escala, como as hidrelétricas, envolvem uma rede de agentes em diferentes espaços conectados por várias obras, compondo um projeto maior, neste caso continental. Tudo isso movido pela lógica do capital global. O Quadro 2 mostra acionistas das principais hidrelétricas da bacia do rio Uruguai, o que evidencia a natureza relacional entre o capital transnacional e os Estados nacionais, que se articulam e se materializam por meio das SPEs.

Embora as hidrelétricas estejam espalhadas pela bacia hidrográfica, conforme se observa no Quadro 2 , as associações se repetem nas diferentes usinas, como é o caso da Companhia Paulista de Força e Luz (CPFL) e da Companhia Estadual de Energia Elétrica (CEEE-RS). Se considerarmos o Sistema Interligado Nacional (SIN), as empresas repetem as alianças ou participam de outros consórcios com empresas diferentes. Furnas (estatal) e Votorantim (privada), por exemplo, conferem à empresa barrageira o know how e a flexibilidade econômica necessária para a expansão dos projetos com instalação de novas usinas hidrelétricas.

Com base nas características dos acionistas, é possível compreender que entre os objetivos principais desses projetos está, sobretudo, a sustentação do desenvolvimento econômico. Em empresas acionistas como a Alcoa ou a Companhia Siderúrgica Nacional (CSN), por exemplo, a energia assume status de matéria-prima, em virtude da grande demanda por beneficiamento de materiais como o alumínio e 
Figura 2

Acionistas das Principais UHEs da Bacia do Rio Uruguai

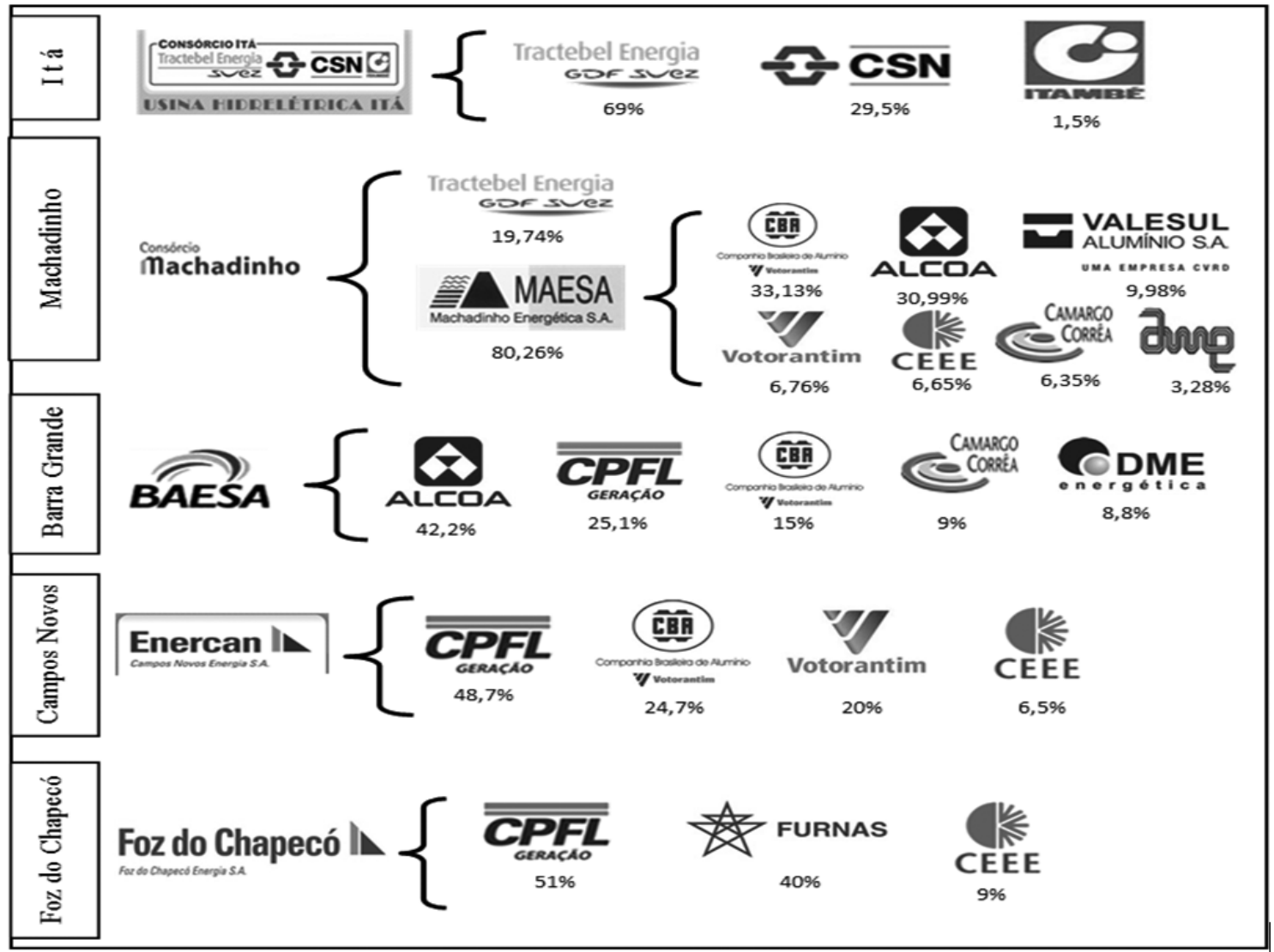

Fonte: Elaborado pelos autores.

o aço. Além disso, merecem destaque empresas que não figuram como acionistas nas hidrelétricas, mas que ocupam lugar estratégico no setor elétrico, como a Engevix, no setor de planejamento e responsável pelos Estudos de Impacto Ambiental e consequentemente pelos Relatórios de Impacto Ambiental (EIA-Rima) de vários projetos hidrelétricos na bacia, além da Voith-Siemens e da Alstom, esta, inclusive, fornecedora de turbinas para hidrelétricas da bacia.

Embora tenhamos consciência de que os projetos globais são mais complexos, procuramos assinalar aqui componentes da concepção de uma hidrelétrica como um "ponto de poder". O fundamental para a nossa análise é compreender, mesmo que sinteticamente, elementos da cristalização de empresas estatais e privadas, nacionais e internacionais, em SPEs. Ademais, tais sociedades agem de forma a identifi- car-se com um projeto neoliberal, que, sem a pretensão de engessar a análise, sugere a natureza da ação desses agentes no que se refere ao conflito inerente às obras de grande escala, como as hidrelétricas. ${ }^{6}$

\section{Os "reassentamentos rurais coletivos"}

Os reassentamentos são considerados "pontos de poder" onde predominam as ações do MAB, e identificados, para fim de análise, com o projeto político democrático-participativo. De forma genérica, Bergamasco e Norder (1996, pp. 7-8) definem os "assentamentos rurais" como sendo a "criação de novas unidades de produção agrícola, por meio de políticas governamentais visando o reordenamento do uso da terra, em benefício de trabalhadores 
rurais sem terra ou com pouca terra". Na mesma linha, os "reassentamentos de populações atingidas por barragens de usinas hidrelétricas" são enquadrados pelos autores como um tipo de assentamento. Apesar disso, vale a pena uma explicação sobre a origem do termo reassentamento.

Durante o processo de instalação da UHE Itá, no rio Uruguai, entre os municípios de Aratiba (RS) e Itá (SC), os dirigentes da $\mathrm{Crab}^{7}$ incorporaram dos técnicos da Eletrosul o uso do termo "reassentamento": "fica implícito que os 'atingidos sem terra” já estavam assentados e, portanto, vão ser 'reassentados', o que, na verdade, não corresponde à realidade dos trabalhadores rurais sem terra" (Moraes, 1994, p. 158). Mesmo que tecnicamente concordemos que os "reassentamentos" correspondam a variaçôes de "assentamentos", é importante assinalar que, no caso das barragens, "o hábito da linguagem fez com que a palavra 'assentamento' tenha praticamente desaparecido do vocabulário dos dirigentes, lideranças e militantes do Movimento dos Atingidos por Barragens" (Idem, ibidem). ${ }^{8}$

Os (re)assentamentos não costumam acontecer de forma deliberada, mas correspondem às tentativas de resposta aos conflitos sociais no campo (Bergamasco e Norder, 1996). Entendendo a hidreletricidade como um processo social que teve início na instalação da primeira hidrelétrica no Brasil, em 1883, podemos dizer que até as décadas de 1970 e 1980 não havia um planejamento prévio para o reassentamento das famílias atingidas por barragens. Nesse período, o remanejamento acontecia "às vésperas da inundação" ou "quase que simultaneamente à subida das águas", como ocorreu em Sobradinho e Itaparica (rio São Francisco, no estado de Pernambuco) na década de 1970 e em Tucuruí (rio Tocantins, no estado do Pará) e Itaipu (rio Paraná, no estado do Paraná) na década de 1980 (Idem).

Embora o movimento social deflagrado pela instalação das hidrelétricas tenha ocorrido em diferentes regióes do Brasil, foi na UHE Itá que se observou o grande salto de qualidade no que se refere ao remanejamento populacional, tanto que, como já assinalamos, o termo teve sua origem nesta circunstância. A questão do remanejamento ali encontrava-se sob a organização da Crab, e com a pressão popular, o movimento social firmou um acordo histórico com a Eletrosul em 17 de outubro de 1987, assinado pelo ministro de Minas e Energia em 6 de novembro do mesmo ano (Moraes, 1994, p. 167). Isso garantiu ao movimento a participação em um grupo de trabalho que, juntamente com representantes de cooperativas e técnicos da Eletrosul, elaborou o "projeto de reassentamento". Assim, viabilizou-se o primeiro núcleo formado por 27 famílias reassentadas no município de Marmeleiro-PR. Todavia, no ano seguinte, "a Eletrosul interrompeu todas as negociações, tanto as indenizações quanto os reassentamentos" (Idem, p. 169). ${ }^{9}$

O projeto de reassentamento pode ser considerado um divisor de águas no remanejamento populacional decorrente da implantação de usinas hidrelétricas. Porém, o fato de se tratar de "um documento feito a muitas mãos", "da maciça presença de técnicos da empresa", e tendo em vista que "o projeto foi construído com base no modelo que se queria em termos de infraestrutura", o sentido político desses reassentamentos acabou diminuído, seja porque "as opções do movimento aparecem misturadas às do Estado", seja porque a presença dos técnicos dos consórcios "dificulta ainda mais a compreensão do direito à terra como resultante da luta dos atingidos mediada pela Crab" (Idem, p. 170-172).

Nesse sentido, vale assinalar uma diferença mais específica entre os assentamentos do Movimento dos Trabalhadores Sem Terra (MST) e os reassentamentos do MAB. Enquanto os primeiros são frutos de mobilizações realizadas principalmente por via de "acampamentos" de "sem terra", os últimos são resultado de um embate entre a empresa barrageira e a população atingida (proprietários de terras ou não). Se o MST qualifica a luta política pelo "tempo de acampamento" (Loera, 2006), o MAB, embora também desenvolva um processo de resistência, não dispõe da mesma força de mobilização, além do que todo o processo é concomitante à "negociação" (Rocha, 2010). Logo, é possível relativizarmos a natureza dos reassentamentos como pontos de mobilização política do MAB nos mesmos moldes que acontece com o MST. Isso é fundamental para a nossa investigação. Os reassentamentos são "processos sociais que envolvem períodos de tempo significativos", "altamente suscetíveis a mudanças nas condições iniciais"; eles "evoluem em 
um campo dominado por relaçóes de poder e são de natureza essencialmente política”. Com efeito, "essa dimensão temporal significa que a configuração de fatores que podem caracterizar um processo na sua fase inicial está aberta a mudanças que se originam, não apenas do seu interior, mas também do seu exterior" (Bartolomé, 2000, pp. 163-165). Além disso, "o simples fato de ser afetado por um projeto não define um grupo no sentido sociológico, a saber, isso não deixa implícita a existência de atributos comuns, nem de objetivos comuns". $\mathrm{O}$ autor reforça ainda que "de fato esses podem ser completamente contraditórios” (Idem, p. 165).

É preciso relativizar, portanto, a ideia de que o processo de reassentamento da população atingida pela implantação de usinas hidrelétricas seja a representação de um projeto democrático-participativo, em contraponto à ideia de que o plano de implantação de hidrelétricas seja a "cristalização" de um projeto neoliberal. Os reassentamentos são concebidos a partir de relações de poder entre o MAB e as SPEs em cada caso especificamente. Se fizermos uma rápida retrospectiva, no caso da UHE Itá (1990) os reassentamentos certamente representaram conquistas do movimento social, mas também foram compreendidos como benefícios decorrentes da instalação da usina. No caso da UHE Campos Novos (2005), os reassentamentos foram realizados a partir da mediação entre a SPE e uma associação que disputou - e suplantou - a representatividade do MAB. Já na implantação da UHE Foz do Chapecó (2010), não obstante o esforço do movimento social, apenas quarenta famílias foram reassentadas a partir da criação de associações organizadas pelo MAB. Essas diferenças refletem a mudança de contexto (privatização do setor elétrico, mudanças nas relações entre mediadores, como sindicatos, igrejas e universidades, e ascensão do Partido dos Trabalhadores ao governo) que transformou também a forma de atuação do MAB (Rocha, 2013).

De qualquer maneira, se pensarmos que a instalação de hidrelétricas ocasiona o deslocamento compulsório da população atingida, os "reassentamentos rurais coletivos", que reúnem famílias de pequenos agricultores organizados, em sua maioria, sob a égide do $\mathrm{MAB}$, criam focos de poder na região atingida de acordo com perspectiva de um proje- to democrático-participativo. Considerando que a bacia do rio Uruguai compreende uma região com mais de trinta projetos hidrelétricos já instalados ou em vias de instalação e 29 reassentamentos decorrentes desses projetos, é importante compreendermos em que medida esses focos influenciam nas relações de poder que compõem a "malha" de análise correspondente à bacia do rio Uruguai (Figura 1).

\section{A "multiterritorialização" do conflito}

Entre as modalidades de remanejamento populacional , o "reassentamento rural coletivo" é o preferido pelo MAB por manter os vínculos de vizinhança, mas, sobretudo, pela possibilidade de transformar latifúndios em áreas de agricultura familiar, alterando a lógica produtiva. Por outro lado, a "carta de crédito" é a modalidade que mais convém às SPEs pela rapidez com que a população é transferida e por ter um custo menor se comparada aos reassentamentos.

Tanto as instalações de hidrelétricas pelas SPEs quanto os respectivos remanejamentos populacionais provocam reconfiguraçôes sociais e alteram os sentidos das territorializaçōes nesses lugares. Observa-se, assim, o que Haesbaert chama de "multiterritorialização": "uma resposta a esse processo identificado por muitos como 'desterritorialização"'. Segundo o autor, para além da perda de um território, o termo propõe a discussão acerca da "complexidade dos processos de (re)territorialização em que estamos envolvidos, construindo territórios muito mais múltiplos", sendo que "estes processos de (multi)territorialização precisam ser compreendidos especialmente pelo potencial de perspectivas políticas inovadoras que eles implicam" (Haesbaert, 2005, p. 6774).

Os projetos hidrelétricos controlam os espaços onde as usinas deverão ser instaladas. Tendo em vista o deslocamento compulsório, o MAB procura agrupar a população atingida em torno da modalidade de reassentamento. Sob a luz de um projeto neoliberal, os consórcios de empresas possibilitam à empresa barrageira a atuação - e o controle - em diversos lugares, a ponto de serem chamados, no caso da região em tela, de "os donos do rio Uruguai" (Paim e Ortiz, 2006, p. 56). Por outro lado, convém veri- 
ficar em que medida aqueles que são representados pelo $\mathrm{MAB}$, para além da desterritorialização ou do simples remanejamento, ao se reagruparem em reassentamentos, têm a possibilidade de "espacialização" e "territorialização" da luta sob a perspectiva de um projeto político democrático-participativo.

Se referindo aos assentamentos do MST, Bernado Fernandes explica que "espacializar é conquistar novos espaços, novos lugares, novas experiências, desenvolver novas formas de luta e, consequentemente, novas conquistas, transformando a realidade, lutando pelo futuro". O assentamento é, continua o autor, "um novo recurso na luta pela terra que significa parte das possíveis conquistas, sobretudo, a possibilidade de territorialização" (1999, p. 136). Evidencia-se nessa passagem uma relação entre os termos "espacialização" e "territorialização", no sentido de que "a fração do território é conquistada na espacialização da luta, como resultado do trabalho de formação e organização do movimento. Assim, o território conquistado é trunfo e possibi- lidade da sua territorialização na espacialização da luta pela terra" (Idem, pp. 241-242). Transportando essa ideia para a análise do processo social referente ao remanejamento populacional decorrente da hidreletricidade, podemos compreender em que medida os reassentamentos refletem na multiterritorialização do conflito entre o MAB e as SPEs do setor hidrelétrico. Para isso, primeiro, é preciso demarcar qual seria a modalidade de remanejamento em que ocorre maior mobilização da população atingida. Em seguida, analisaremos as motivações dessa população de forma a apurar a relação entre mobilização, modalidade de remanejamento e ação de seus propositores.

Para uma discussão a esse respeito, selecionamos uma questão do survey proposta às famílias remanejadas em decorrência das cinco principais hidrelétricas da bacia do Uruguai: "Depois do seu remanejamento, o(a) Sr(a) participou de mobilização de apoio a outros atingidos?". Com base nos resultados, elaboramos Quadro 2.

Quadro 2

Envolvimento da População Atingida em Mobilizaçôes após o seu Remanejamento

\begin{tabular}{|c|c|c|c|c|c|c|c|c|c|}
\hline & & \multicolumn{7}{|c|}{ Modalidade de Remanejamento } & \multirow{2}{*}{ Total } \\
\hline & & RAR & PRR & RRC & $\mathrm{CC}$ & Dinheiro & RU & Acordo & \\
\hline \multirow[t]{3}{*}{ Sim } & Quantidade & 16 & 5 & 136 & 53 & 49 & 4 & 4 & 267 \\
\hline & $\%$ entre as respostas Sim & $6 \%$ & $1,9 \%$ & $50,9 \%$ & $19,9 \%$ & $18,4 \%$ & $1,5 \%$ & $1,5 \%$ & $100 \%$ \\
\hline & $\%$ dentro da modalidade & $43,2 \%$ & $20,8 \%$ & $59,1 \%$ & $29,4 \%$ & $36,3 \%$ & $19,0 \%$ & $100 \%$ & $42,3 \%$ \\
\hline \multirow[t]{3}{*}{ Não } & Quantidade & 21 & 18 & 93 & 125 & 86 & 16 & 0 & 359 \\
\hline & \% entre as respostas Não & $5,8 \%$ & $5 \%$ & $25,9 \%$ & $34,8 \%$ & $24 \%$ & $4,5 \%$ & $0 \%$ & $100 \%$ \\
\hline & $\%$ dentro da modalidade & $56,8 \%$ & $75 \%$ & $40,4 \%$ & $69,4 \%$ & $63,7 \%$ & $76,2 \%$ & $0 \%$ & $56,9 \%$ \\
\hline \multirow[t]{2}{*}{ NS } & Quantidade & 0 & 0 & 1 & 1 & 0 & 0 & 0 & 2 \\
\hline & \% em relação ao Total & $0 \%$ & $0 \%$ & $0,2 \%$ & $0,2 \%$ & $0 \%$ & $0 \%$ & $0 \%$ & $0,3 \%$ \\
\hline \multirow[t]{2}{*}{ NR } & Quantidade & 0 & 1 & 0 & 1 & 0 & 1 & 0 & 3 \\
\hline & \% em relação ao Total & $0 \%$ & $0,2 \%$ & $0 \%$ & $0,2 \%$ & $0 \%$ & $0,2 \%$ & $0 \%$ & $0,5 \%$ \\
\hline \multirow[t]{2}{*}{ Total } & Entrevistados & 37 & 24 & 230 & 180 & 135 & 21 & 4 & 631 \\
\hline & \% em relação ao Total & $5,9 \%$ & $3,8 \%$ & $36,5 \%$ & $28,5 \%$ & $21,4 \%$ & $3,3 \%$ & $0,6 \%$ & $100 \%$ \\
\hline
\end{tabular}

RAR: Reassentamento em Áreas Remanescentes; PRR: Pequenos Reassentamentos Rurais; RRC: Reassentamentos Rurais Coletivos; CC: Cartas de Crédito; RU: Reassentamento Urbano; NS/NR: Não Sabe ou Não Respondeu.

Fonte: Elaborado pelos autores. 
O quadro oferece uma visão geral das modalidades de remanejamento e a participação dos atingidos em mobilizaçôes sociais. Entre as duas modalidades focadas nesta análise, o "reassentamento rural coletivo" se destaca em termos de mobilização: seis em cada dez entrevistados participaram de mobilizações após serem remanejados. Em contrapartida, a "carta de crédito" apresenta um índice menor da participação: três em cada 10 entrevistados. Se considerarmos o total de participantes em mobilizaçōes, em cada dez, seis entrevistados vieram de reassentamentos, ao passo que apenas dois foram autorreassentados (isto é, indenizados através de "carta de crédito"). Isso mostra a preferência do MAB pela modalidade de RRC, e da SPE, pela "carta de crédito".

Em outras oportunidades afirmamos que fatores como a aglomeração nos reassentamentos, ao contrário do que acontece no caso das "cartas de crédito", influenciaram o grau de mobilização das famílias após o remanejamento (Rocha, 2010; 2013). Todavia, concluímos que seria preciso aprofundar a análise utilizando métodos mistos para se chegar a uma resposta menos superficial. Lieberman (2005, p. 440) chama a atenção para o "valor sinérgico" de uma análise que mescla métodos quantitativos e qualitativos, uma vez que os primeiros permitem

Quadro 3

Quadro das Motivaçóes dos Remanejados

\begin{tabular}{|c|c|c|}
\hline Resposta & Sentido & Motivação \\
\hline \multirow{4}{*}{ Sim } & Solidariedade Humana & $\begin{array}{l}\text { "para ajudar o próximo", "gostaria que todos conseguissem o mesmo que } \\
\text { eu"; "ajudar aqueles que sofrem como a gente sofreu"; "um ajuda o outro, } \\
\text { tem que ser assim, né". }\end{array}$ \\
\hline & $\begin{array}{l}\text { Alinhamento com o } \\
\text { MAB }\end{array}$ & $\begin{array}{l}\text { "porque somos todos companheiros"; "para ajudar os outros atingidos"; } \\
\text { "pela reforma agrária"; "passar minha experiência"; "defender os direitos dos } \\
\text { atingidos"; "porque somos todas da mesma classe"; "porque eu participo } \\
\text { do movimento das mulheres"; "para ajudar os sem terra"; "para sair mais } \\
\text { reassentamentos". }\end{array}$ \\
\hline & Interesses específicos & $\begin{array}{l}\text { "para ajudar outros pescadores"; "para pedir maquinário pro } \\
\text { reassentamento"; "para buscar melhorias pra comunidade"; "para renegociar } \\
\text { a dívida com o banco"; "por causa de uns familiares meus que precisavam"; } \\
\text { "para a reforma das casas"; "pra garantir mais verba pro reassentamento". }\end{array}$ \\
\hline & Retribuição & "ajudar quem nos ajudou”; "fui ajudado e me sinto na obrigação". \\
\hline \multirow{4}{*}{ Não } & Trabalho na propriedade & $\begin{array}{l}\text { "a gente só tem tempo pro serviço"; "não tenho ninguém pra deixar na } \\
\text { propriedade"; "não dá, tem que trabalhar". }\end{array}$ \\
\hline & Acomodação & $\begin{array}{l}\text { "aqui nós já tamo colocado"; "recebi uma Carta e não me preocupei mais"; } \\
\text { "eu já tô satisfeito"; "eu me acomodei e não quis mais saber". }\end{array}$ \\
\hline & Individualismo & $\begin{array}{l}\text { "a minha luta já acabou, não tenho que me meter"; "eu fui cuidar da minha } \\
\text { vida"; "as pessoas de cada município têm que se organizar"; "já que me } \\
\text { lasquei, que se lasquem também". }\end{array}$ \\
\hline & $\begin{array}{l}\text { Alinhamento com os } \\
\text { empreendedores }\end{array}$ & $\begin{array}{l}\text { "a empresa é boa pra nós"; "eu já tinha acertado com a empresa que não ia } \\
\text { participar de manifestação"; "fizemos um acordo com o consórcio"; "se não } \\
\text { acertar numa boa, não tem jeito". }\end{array}$ \\
\hline Outros & \multicolumn{2}{|c|}{$\begin{array}{l}\text { "aqueles que não participaram alegaram motivações como "nunca me chamaram", "era muito longe", } \\
\text { "não gosto de invasão, a gente fica malvisto", "minha mãe tava doente". Já os que participaram alegaram } \\
\text { "pedidos de vizinhos e família", "curiosidade", "conhecer outros lugares". }\end{array}$} \\
\hline
\end{tabular}

Fonte: Elaborado pelos autores. 
a observação do conjunto de dados e os segundos, uma análise causal mais aproximada. Assim, fizemos uso de entrevistas em profundidade para entendermos melhor como a mobilização dos cidadãos reflete na "multiterritorialização" do conflito e qual seria a influência do MAB nesse processo. Pedimos, então, aos entrevistados que manifestassem os motivos da participação ou não em mobilizações sociais no período posterior ao seu remanejamento. Para a elaboração do Quadro 3 não nos detivemos em análises estatísticas, nem seria este o objetivo, pois a ambiguidade das respostas comprometeria certamente a exatidão dos dados. Por exemplo, uma resposta como "ajudar um compadre" poderia ser classificada tanto no grupo "solidariedade humana", como na categoria "retribuição" ou mesmo "interesse próprio". No contexto da metodologia qualitativa, optamos por elencar as motivações da maior para a menor frequência, de forma que, entre as respostas "sim" - que participaram de manifestações após o remanejamento -, foram mais frequentes as motivações que classificamos como de "solidariedade humana" (40\%), "alinhamento com o MAB" (20\%), "interesses específicos" (20\%) e "retribuiçãa” (10\%); entre as respostas "não" - que não haviam participado de manifestações após o remanejamento -, as mais frequentes foram classificadas como "trabalho na propriedade" (40\%), "acomodação" (30\%), "individualismo" (15\%) e "alinhamento com os empreendedores" (5\%). Foram observadas também respostas variadas e inconsistentes, classificadas no grupo "outros", que não interferiu em nossas conclusōes.

A solidariedade humana é com certeza o principal fator para a participação em movimentos sociais na região, independentemente da modalidade de remanejamento. Mas, para além dos motivos que determinaram sua participação, os grupos que foram remanejados a partir da modalidade incentivada pelo MAB - "reassentamento rural coletivo" sobressaíram nos resultados do levantamento.

\section{Conclusão}

Com quase um século e meio no Brasil, o processo social referente à hidreletricidade na bacia do rio Uruguai pode ser retomado a partir da década de 1960, quando a exploração do potencial elétrico foi assumida de forma sistemática. Nesse processo, agentes sociais envolvidos em relaçóes de poder que se intensificam em cada hidrelétrica a ser instalada podem ser identificados, para fins de análise, sob duas perspectivas que correspondem a dois projetos políticos distintos, o neoliberal e o democrático-participativo.

$\mathrm{Na}$ "malha de análise" resultante da pesquisa, cada hidrelétrica e seus respectivos reassentamentos representam "pontos de poder" que possibilitam um processo de "multiterritorialização" do conflito entre o MAB (sob a luz de um projeto democrático-participativo) e as SPEs (como concretização do projeto neoliberal). Entre as modalidades de remanejamento, a "carta de crédito" mostra-se mais adequada aos objetivos das SPEs, por conta da redução significativa de custos aos cofres das empresas. Já na perspectiva do $M A B$, a modalidade "reassentamento rural coletivo" parece mais interessante pelo fato de favorecer a mediação do movimento com as famílias agrupadas e condizer melhor com os objetivos de reforma agrária e mudança no sistema produtivo, bandeiras do MAB para além do questionamento ao setor elétrico.

Considerando apenas as maiores hidrelétricas da bacia e seus respectivos remanejamentos populacionais, vislumbramos na região as possibilidades de "multiterritorialização" do conflito. Nessa perspectiva, embora o RRC ainda seja o principal núcleo de mobilização pós-remanejamento, a maior motivação para participar de novas manifestações se dá principalmente em decorrência da "solidariedade humana" e não por ação de uma formação pedagógica desenvolvida pelo MAB. Sem menosprezar o trabalho desse movimento social, a não participação em manifestaçôes pós-remanejamento é causada não só por certa acomodação, mas também pelo fato de os agricultores não "poderem" ou não "quererem" se afastar das novas propriedades, ainda que tenham consciência de que sem a ajuda mobilizada pelo MAB a conquista de sua propriedade teria sido mais difícil ou mesmo impossível.

Esta confluência de fatores aponta para o fato de que o projeto neoliberal tende a fortalecer a "multiterritorialização" em cada nova hidrelétrica instalada, seja mantendo os mesmos acionistas, seja 
interagindo efetivamente com as populações locais remanescentes. Por outro lado, o projeto democrático-participativo encara a dispersão da população, ocasionada pelo remanejamento através das "cartas de crédito" - que crescem de maneira inversamente proposicional aos reassentamentos em cada nova hidrelétrica -, como um grande problema, pois evidentemente isso dificulta a mobilização social. Embora a participação em movimentos sociais ocorra com mais intensidade nos reassentamentos coletivos, a principal motivação para isso não tem a ver com um "alinhamento aos ideais defendidos no $M A B$ ”, o que comprova a necessidade de uma revisão no processo pedagógico de conscientização desenvolvido entre a comunidade local.

Em suma, este estudo pôde mostrar que a sucessão de hidrelétrica tende a consolidar os ideais condizentes com um projeto neoliberal a partir da primazia do mercado e do desenvolvimentismo. Por outro lado, os reassentamentos, focos privilegiados para a atuação do movimento social, não apresentam o mesmo potencial no sentido de um projeto democrático-participativo que prime pela participação das comunidades locais e a manutenção do seu modo de vida. Seria um engano acreditarmos em uma conclusão definitiva a esse respeito, mas abrimos aqui precedentes para a análise da evolução dos movimentos sociais, sobretudo do MAB, assim como da atuação das empresas (estatais e privadas, nacionais e multinacionais) que compõem o setor elétrico brasileiro.

\section{Notas}

1 Considera-se as Centrais Geradoras Hidrelétricas $(\mathrm{CGH})$ as usinas com até $1 \mathrm{MW}$ de potência instala$\mathrm{da}$; as Pequenas Centrais Hidrelétricas $(\mathrm{PCH})$, entre 1,1 MW e 30 MW de potência instalada; e as Usinas Hidrelétricas de Energia (UHE), com mais de 30 MW de potência instalada, sendo que estas correspondem a aproximadamente $65 \%$ da geração hidrelétrica brasileira.

2 Segundo Magalhães (2007, p. 14), o termo designa "o processo pelo qual determinados grupos sociais, em circunstâncias sobre as quais não dispõem de poder de deliberação, são obrigados a deixar ou a transferir-se de suas casas e/ou de suas terras. Há, portanto, um conteúdo de cerceamento do poder decisório no interior do próprio grupo social, advindo de uma intervenção externa”. A autora analisa o termo considerando as instâncias pública, acadêmica e o caso específico de Tucuruí, demonstrando a relação deste deslocamento com aspectos como "stress", "sofrimento social" e "constrangimento". É certo que esses fatores estão associados ao "deslocamento compulsório", porém, para a nossa discussão, a contribuição maior está no fato de que o termo serve como um "guarda-chuva" onde se abrigam termos como "relocação, reassentamento, reinstalação, transferência de população; e alguns outros que designam fases intermediárias de processos de deslocamento, como indenização, desapropriação" (Idem, pp. 113-114).

3 Sociedades de Propósito Específico (SPE) são empresas criadas especificamente para construir e operar uma usina hidrelétrica. Elas são fundamentadas na Lei n. 11079 , de 30 de dezembro de 2004, que estabelece as normas gerais para as parcerias público-privadas.

4 Sobre as particularidades das modalidades, ver Rocha (2012b).

5 O SPSS (Statistical Package for the Social Sciences ou Pacote Estatístico para as Ciências Sociais) é um software que possibilita testes estatísticos de correlação e frequência entre variáveis relativas a pesquisas em ciências sociais.

6 A forma como se dá a inserção de projetos globais nos respectivos locais na perspectiva da IIRSA e das SPEs foi tratado mais detalhadamente em Rocha (2012a).

7 A Comissão Regional dos Atingidos por Barragens (Crab), organizada no final da década de 1970 na bacia do Uruguai ante a instalação das UHEs Itá e Machadinho, pode ser considerada o embrião do Movimento dos Atingidos por Barragem (MAB).

8 Embora acreditemos que o termo "reassentamento" seja mais adequado aos atingidos por barragens, para além de qualquer diferença mais específica, vale à pena a lembrança de Zimmermann (1994, pp. 206-207) ao assinalar que os assentamentos representam a luta pela terra, o que, de certa forma, identifica os agricultores para além de interesses individuais. Segundo a autora, esta suposta "homogeneização" tem como marco a Fazenda Anoni, no município de Sarandi-RS, que, embora seja reconhecida como reduto do Movimento dos Sem Terra (MST), foi inicialmente desapropriada pelo Incra em 1972 para fins de reassentamento de agricultores atingidos por barragens. O que importa, então, é que esses espaços remetem aos agricultores que, por diferentes motivos, lutam pela terra. 
9 Em 1998 a Eletrosul - já em um contexto de privatização - implantou a modalidade "carta de crédito" ou autorreassentamento "à revelia da Crab" (Reis, 2001, p. 157), assinalando o antagonismo entre perspectivas identificadas com os dois projetos políticos discutidos aqui. Inicialmente, a "carta de crédito" foi estabelecida para valorar a situação dos que não eram proprietários, chegando a ser concebida como uma conquista do próprio movimento social. Depois, isso foi absorvido pelo empreendedor e passou a representar um problema para o movimento social, pois a carta de crédito foi estendida também aos proprietários, passando a representar uma alternativa aos reassentamentos, conforme detalhamos em outra oportunidade (Rocha, 2009).

\section{BIBLIOGRAFIA}

ANEEL - Agência Nacional de Energia Elétrica. (s. d.). Banco de Informações de Geração - BIG. Disponível em www.aneel.gov.br/aplicacoes/ capacidadebrasil/capacidadebrasil.cfm, consultado em 27 fev. 2014.

ARAÚJO, Maria Lia Corrêa de. (1994), "A experiência de organização dos reassentados de Itaparica", in Leonilde Medeiros et al. (orgs.), Assentamentos rurais: uma visäo multidisciplinar, São Paulo, Editora da Unesp, pp. 237-247.

BARTOLOMÉ, Leopoldo José. (2000), "Esquema de reassentamento populacional como processos sociais: questôes conceituais e metodológicas", in Walter Arensberg (org.), Barragens, desenvolvimento e meio ambiente, São Paulo, s. ed., pp. 163-167.

BERGAMASCO, Sônia Maria \& NORBER, Luiz Antônio Cabello Norber. (1996), O que são reassentamentos rurais. São Paulo, Brasiliense.

BRASIL. Lei n. 9074, de 7 de julho de 1995. "Estabelece normas para outorga e prorrogaçóes das concessões e permissōes de serviços públicos e dá outras providências". Brasília.

DAGNINO, Evelina; OLVERA, Alberto J. \& PANFICHI, Aldo. (2006), "Para uma outra leitura da disputa pela construção democrática na América Latina", in (orgs.), $A$ disputa pela construção democrática na America Latina, São Paulo/Campinas, Paz e Terra/Editora da Unicamp.
ELIAS, Norbert. (2006), Escritos \& ensaios. Vol. 1: Estado, processo e opinião pública. Rio de Janeiro, Jorge Zahar.

FERNANDES, Bernardo Mançano. (1999), MST: Movimento dos trabalhadores rurais sem terra: formação e territorialização em São Paulo. 2. ed. São Paulo, Hucitec.

HAESBAERT, Rogério. (2005), "Da desterritorialização à multiterritorialidade". Anais do X Encontro de Geógrafos da América Latina, São Paulo, pp. 6774-6792.

IANNI, Octavio. (1997), A sociedade global. 5. ed. Rio de Janeiro, Civilização Brasileira.

LIEBERMAN, Evans S. (2005), "Nested analysis as a mixed-method strategy for comparative research. American Political Science Review, 99 (3): 435-452.

LOERA, Nashieli Rangel. (2006), A espiral das ocupaçôes de terra. São Paulo/Campinas, Polis/Ceres/IFCH - Unicamp.

MAGALHÃES, Sonia Barbosa. (2007), Lamento e Dor: uma análise socioantropológica do deslocamento compulsório provocado pela construção de barragens. Tese de doutorado, Belém, Universidade Federal do Pará em cotutela com a École Doctorale Vivant et Sócietés da Universidade Paris 13.

MORAES, Maria Stela Marcondes de. (1994), "Reassentamentos de atingidos pelas barragens do rio Uruguai", in Leonilde Medeiros et al. (orgs.), Assentamentos rurais: uma visão multidisciplinar, São Paulo, Editora da Unesp, pp. 157-175.

NICOLAS, Daniel Hiernaux. (1996), "Tempo, espaço e apropriaçãa social do território: rumo à fragmentação na mundialização?", in Milton Santos, Maria Laura Silveira e Maria Adelia A. de Souza (coords.), Território: globalização e fragmentação, 3. ed., São Paulo, Hucitec.

PAIM, Elisangela Soldatelli \& ORTIZ, Lúcia Schild (orgs.). (2006), Hidrelétricas na bacia do rio Uruguai: guia para ONGs e movimentos sociais. Porto Alegre, NAT/Brasil.

RAFFESTIN, Claude. (1993), Por uma geografia do poder. São Paulo, Ática.

REIS, Maria José. (2001), "O reassentamento de pequenos produtores rurais: o tempo da re- 
construção e recriação dos espaços", in Maria José Reis e Neusa Maria Sens Bloemer, Hidrelétricas e populaçôes locais. Florianópolis, Cidade Futura/Editora da UFSC, pp. 119-166.

RIBEIRO, Gustavo Lins. (1991), Empresas transnacionais: um grande projeto por dentro. São Paulo, Marco Zero/Anpocs.

ROCHA, Humberto José da. (2009), "Carta aos atingidos: as negociaçóes na bacia do rio Uruguai”. Anais do I Seminário Nacional Sociologia \& Politica, Curitiba.

. (2010), "A condição de atingido por barragem". Anais do I Seminário Internacional e III Seminário Nacional Movimentos Sociais, Participação e Democracia, Florianópolis, pp. 386-400.

(2012a), "Integração desintegradora: a trajetória de projetos hidrelétricos desde a IIRSA até as comunidades locais". Mural Internacional, 3: 30-36.

. (2012b), "As modalidades de remanejamento", in Marcelo Baquero e Hemerson Luiz Pase, Estado, democracia e hidreletricidade no Brasil, Pelotas, Editora Universitária/UFPel, pp. 113-134.

. (2013), Relaçôes de poder na instalação de hidrelétricas. Passo Fundo (RS), EdiUPF.

ROMANO, Jorge Osvaldo. (1994), "Poder, valores e conflito nos processos de organização no interior dos assentamentos: comentários a um debate", in Leonilde Medeiros et al. (orgs.), Assentamentos rurais: uma visão multidisciplinar. São Paulo, Editora da Unesp, pp. 249-258.

VERDUM, Ricardo. (2007), "Obras de infraestrutura no contexto da integração sul-americana”, in __ (org.), Integração, usinas hidroelé-

tricas e impactos socioambientais, Brasília, Inesc, pp. 13-40.

ZIMMERMANN, Neusa de Castro. (1994), “Os desafios da organização interna de um assentamento rural" in Leonilde Medeiros et al. (orgs.), Assentamentos rurais: uma visão multidisciplinar. São Paulo, Editora da Unesp, pp. 205-224. 



\section{O CONFLITO SOCIAL E POLÍTICO NAS HIDRELÉTRICAS DA BACIA DO URUGUAI}

\section{Humberto José da Rocha e Hemerson Luiz Pase}

Palavras-chave: Conflito social; Movimento dos Atingidos por Barragens; Reassentamentos; Sociedade de Propósito Específico.

No Brasil, a geração de energia é proveniente sobretudo de fonte hidrelétrica, exigindo a construção de obras de infraestrutura que impulsionam um processo social contraditório. Nesse processo, vislumbramos o conflito entre as Sociedades de Propósito Específico (SPEs), proponentes das hidrelétricas, e o Movimento dos Atingidos por Barragens (MAB), representante de segmentos das populaçôes locais deslocadas compulsoriamente. Tendo como locus a bacia do Uruguai, no Sul do Brasil, este artigo discute esse conflito no quadro formado por hidrelétricas e reassentamentos. Procuramos compreender a frequência e as motivações da comunidade atingida em participar politicamente de mobilizações contra hidrelétricas após já ter sido remanejada. Para tanto, utilizamos uma metodologia que articula instrumentos qualitativos e quantitativos baseados em pesquisa empírica.

\section{SOCIAL AND POLITICAL CONFLICT OVER HYDROELECTRIC POWER PLANTS IN THE URUGUAY RIVER BASIN}

\section{Humberto José da Rocha and Hemerson Luiz Pase}

Keywords: Social conflict; Movement of the Affected by Dams; Resettlement; Special Purpose Company.

In Brazil, power generation is mainly provided by hydroelectric sources, requiring the construction of infrastructure works that propel a contradictory social process. In this process, one observes the conflict between the Specific Purpose Entities (SPEs), the proponents of hydroelectric power plants, and the Movement of People Affected by Dams (MAB), which represents the local populations compulsorily dislocated. Focusing the basin of the Uruguay River, in southern Brazil, this article discusses such conflict through a frame of analysis involving the hydroelectric plants and the resettlements. In so doing, it seeks to understand the frequency and the motivations of the affected populations, after their relocation, to participate politically in mobilizations against hydroelectric power plants. The analysis uses use a methodology that articulates qualitative and quantitative instruments based on empirical research.

\section{LE CONFLIT SOCIAL ET POLITIQUE DANS LES USINES HYDROÉLECTRIQUES DU BASSIN DE L'URUGUAY}

\author{
Humberto José da Rocha et \\ Hemerson Luiz Pase
}

Mots clés: Conflit social; Mouvement des Affectées par les Barrages; Réinstallations; Société à Finalité Spécifique.

Au Brésil, la production d'électricité provient essentiellement de sources hydroélectriques. Cela exige la construction d'infrastructures qui stimulent un processus social contradictoire. Dans ce processus, nous entrevoyons le conflit entre les Société à Finalité Spécifique (SPEs), les promoteurs des hydroélectriques, et le Mouvement des Affectées par les Barrages (MAB), qui représente les populations locales déplacées de façon obligatoire. Ayant pour exemple le bassin du fleuve Uruguay, dans le Sud du Brésil, cet article aborde ce conflit dans un cadre d'usines hydroélectriques et de réinstallation de populations. Nous tentons ainsi de comprendre la fréquence et les motivations de la communauté affectée de participer politiquement à des manifestations contre les usines hydroélectriques postérieurement à leur déplacement et réinstallation. Nous utilisons, pour cela, une méthode qui articule des instruments qualitatifs et quantitatifs fondés sur la recherche empirique. 